\title{
Axon-Glia Interactions Regulate ECM Patterning in the Postnatal Rat Olfactory Bulb
}

\author{
M. de L. Gonzalez and J. Silver \\ Department of Neurosciences, Case Western Reserve University, School of Medicine, Cleveland, Ohio 44106-4975
}

It has been suggested that an inhibitory ECM containing chondroitin-6-sulfate proteoglycan (C-6S-PG) and tenascin (TN), which appears homogeneously in the core of the OB following afferent fiber arrival, helps position ingrowing olfactory axons in the prospective glomerular layer (GL) (Gonzalez and Silver, 1992; Gonzalez et al., 1993). Later, a similar ECM associated with astrocytes envelopes axonal glomeruli in rings, suggesting that axons may control the precise ECM patterning. The question remains whether formation of the matrix ring pattern around each axonal glomerulus is an intrinsic property of the matrix-producing cells or a response to developing axons. To determine if the organization of glial associated matrix in the $O B$ was dependent on the presence of axons, we studied the effect of unilateral injection of a neurotoxin into the olfactory epithelium of postnatal rats. Using olfactory marker protein (OMP), $\beta$-tubulin (TUJ1) antibodies, and Nissl staining, we found that at 5 and $10 \mathrm{~d}$ following neurotoxin administration the number of glomeruli decreased by an average of $77.0 \%$ in the injected side. At the same time, we observed that the TN/C-6S-PG rings and periglomerular cells were present only around the remaining small number of glomeruli. Elsewhere, ECM expression and the periglomerular cell configuration were more disorganized in the GL. The pattern of glial fibrillary acidic protein (GFAP) did not change significantly. We found that OMP staining, $\beta$-tubulin immunoreactivity, and periglomerular cells reformed in a glomerular-like pattern as the olfactory axons reformed by $20 \mathrm{~d}$. As the glomeruli-shaped collection of axon terminals reappeared, TN/C-6S-PG immunoreactivity also reoccurred in rings around the new axon bundles. Again, at this later stage, the expression of GFAP was similar in both sides. In our previous study (Gonzalez et al., 1993), we suggested that the initial gross positioning of glomeruli may be controlled by the overall positioning of TN/C-6S-PG. In the present study, we suggest that the formation of TN/C-6SPG in the precise ring pattern around glomeruli appears to be dependent upon the presence of bundled olfactory axons. Various mechanisms are discussed that may explain the dynamic change in ECM expression that occurs inside the glomerulus after the neurotoxin treatment.

\footnotetext{
Received Sept. 1, 1993; revised Mar. 28, 1994; accepted Apr. 13, 1994.

We thank Catherine Doller for her excellent assistance. This work was supported by NIH Grant NS-25713 and a minority supplementary grant.

Correspondence should be addressed to Maria de L. Gonzalez, Department of Neurosciences, Case Western Reserve University, 10900 Euclid Avenue, Cleveland, $\mathrm{OH} 44106-4975$.

Copyright (C) 1994 Society for Neuroscience $0270-6474 / 94 / 146121-11 \$ 05.00 / 0$
}

IKey words: proteoglycan, axon boundaries, olfactory nerve, axon guidance, regeneration, olfactory bulb, zinc sulfate]

The olfactory bulb (OB) is the first CNS synaptic relay for peripheral olfactory axons within the CNS (Golgi, 1875; Ramon y Cajal, 1911; Allison, 1951; Valverde, 1965; Gesteland et al., 1982). This region is of great importance, not only for its role as a sensory integration center, but also as a model system for regeneration studies. It is the only place in the mammalian CNS that exhibits significant regrowth of its peripherally innervating axons with substantial restoration of function (Monti-Graziadei and Graziadei, 1979; Graziadei and Monti-Graziadei, 1980; Monti-Graziadei et al., 1980; Brunjes and Frazier, 1986).

The $O B$ is characterized by the curious bundling pattern of its afferent axons into glomeruli that do not grow deeply into the brain. Previous studies by us (Gonzalez et al., 1993) and others (Tolbert and Oland, 1990; Gascuel and Mason, 1991; Valverde et al., 1992; Bailey and Shipley, 1993; Goodman et al., 1993) have suggested that the interaction between olfactory axons and bulb glia may help form the axonal glomerular pattern. Gonzalez et al. (1993) suggested that astroglial-associated ECM molecules, tenascin (TN), and chondroitin-6-sulfate-containing proteoglycan (C-6S-PG), which are present in the core of the early developing $\mathrm{OB}$ prior to glomeruli development, form a molecular "wall" that helps confine olfactory axons within the olfactory nerve layer (ONL) at the outer edge of the astroglial territory. Once glomeruli form, the "wall" expands peripherally to surround each glomerulus.

A similar compartmental pattern of glycoconjugate rings has been described in the somatosensory cortex (Cooper and Steindler, 1986a; Steindler et al., 1990). Here, ECM rings are associated with intensely glial fibrillary acidic protein (GFAP)-positive astrocytes (Cooper and Steindler, 1986b; Steindler et al., 1990) around somatosensory cortical "barrels" that are related to individual facial vibrissae. In this region, three boundary molecules have been found, the glycoprotein TN (Crossin et al., 1989; Steindler et al., 1989, 1990) and two types of proteoglycans. The first is cytotactin binding proteoglycan (CTB-PG) (Hoffman et al., 1988; Crossin et al., 1989) and the second is a proteoglycan named neurocan (Margolis and Margolis, 1993) bearing the epitope 1G2 (Oohira et al., 1994). It has been suggested that neurocan is synthesized largely by neurons (Margolis and Margolis, 1993). During the critical period, which in the somatosensory cortex appears to end sometime between postnatal days 1 and 5, lesions of the vibrissae-follicles affect maintenance of the barrels (Van der I oos and Woolsey, 1973; Weller and Johnson, 1975) and their associated boundary ECMs (Crossin et al., 1989; Steindler et al., 1990). 


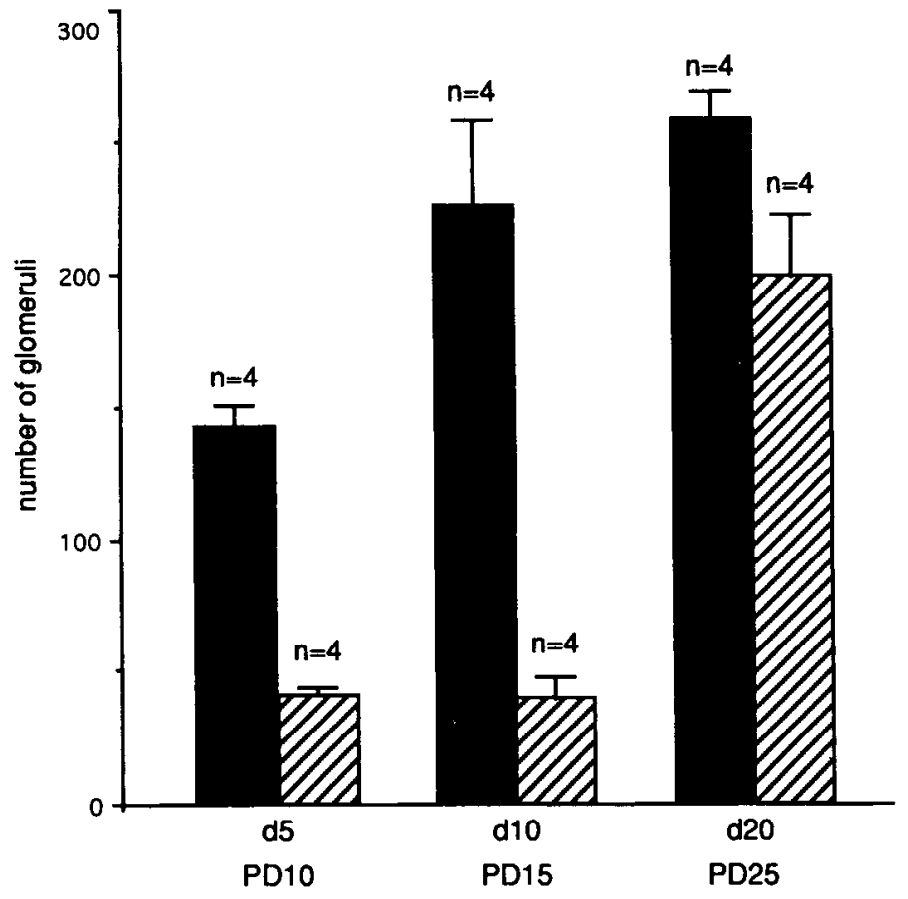

Figure 1. The number of glomeruli was counted over a distance of $750 \mu \mathrm{m}$ of rostral, coronally sectioned tissue after neurotoxin injection. The solid bars represent the number of glomeruli in control sides after 5,10 , and $20 \mathrm{~d}$, respectively; the hatched bars represent the same in the experimental sides after the same range of days. Note that the number of glomeruli decreases $71.7 \%$ after $5 \mathrm{~d}$ and $82.3 \%$ after $10 \mathrm{~d}$, but increases to $22.9 \%$ after $20 \mathrm{~d}$. $n=4$ in each case, although more than four animals were found to exhibit the same pattern. The additional three animals in various groups were partially damaged during the tissue processing and did not have the complete coronal section.

What dictates the formation of compartmentalized neuronal patterns in regions in which both neurons and glia could potentially participate? Some suggest that glia play a vital role (Bailey and Shipley, 1992, 1993; Valverde et al., 1992), while others maintain that axons are the players of primary importance (Van der Loos and Woolsey, 1973; Woolsey and Wann, 1976; Graziadei and Monti-Graziadei, 1980; Crossin et al., 1989; Erzurumlu and Jhaveri, 1992). Evidence supporting the concept that glia are important in synaptic patterning comes from Tolbert and Oland (1990), who studied the development of insect olfactory glomeruli. This study has shown that glial elements define edges for the ingrowing dendrites of second-order olfactory neurons and primary olfactory axons. Exposure to $\gamma$-irradiation or injection of hydroxyurea, which reduced the number of glial cells in the moth olfactory lohe, disrupted the "condensation" of neuropil into glomeruli (Tolbert and Oland, 1990). The idea that axons were clearly significant was reinforced by studies of the developing barrel boundaries, where the precocious arrival of axons from the thalamus prior to barrel boundary formation was carefully documented (Erzurumlu and Jhaveri, 1992). In addition, primary visual cortex was transplanted into the primary somatosensory cortex (Schlaggar and O'Leary, 1991), where it was found that the characteristic barrel-like matrix pattern could develop in the transplanted tissue. Furthermore, it has been demonstrated that the expression of certain proteoglycans, such as Cat-301, is dependent upon neuronal activity. Studies on the effects of early visual deprivation suggest that neuronal activity during the critical period of the developing central visual pathways upregulates the expression of the Cat301 proteoglycan (Zaremba et al., 1989). Other studies demonstrated that Cat-301 expression on the surface of hamster motor neurons requires input by large-diameter primary afferents (Kalb and Hockfield, 1990a). During this early postnatal period its expression on motor neurons could be inhibited by blockade of the NMDA receptor at the spinal segmental level (Kalb and Hockfield, 1990b). If glia play a role in this process, it remains unclear what forms of normal neuronal activity glial cells can react to and how glial pattern information is conveyed to their neuronal counterparts.

There is good experimental evidence that when used as substrates in vitro several glial-associated ECM molecules, TN (Faissner and Kruse, 1990; Lochter et al., 1991; Perez and Halfter, 1993; Taylor et al., 1993), certain keratan sulfatc (KS)containing proteoglycans (Snow et al., 1990; Cole and McCabe, 1991; Brittis et al., 1992; Geisert and Bidanset, 1993), and certain CS-bearing proteoglycans (Snow et al., 1990; Oohira et al., 1991, 1994; Ethell, 1993; Grumet et al., 1993), are capable of inhibiting neurite outgrowth. Indeed, their presence in the bulb (Gonzalez et al., 1993) and throughout the entire neocortex (Oohira et al., 1994) in a layered pattern prior to axon invasion could be an important factor in positioning the site of glomeruli or barrel formation, a response property that may be unique to only certain subtypes of axons. The in vitro studies have been correlated with developmental (Cooper and Steindler, 1986a; Crossin et al., 1989; Steindler et al., 1990; Valverde et al., 1992; Bailey and Shipley, 1993; Gonzalez et al., 1993; Silver et al., 1993) and regeneration studies of other regions (Goldberger, 1974; Kliot et al., 1990; present study) and suggest that glial matrix glycoconjugates (like TN, CS-PG), when in high amounts relative to growth-promoting molecules, can form barriers to developing and regenerating axons in order to constrain or maintain compartmental patterns throughout the CNS. The purpose of the present study was to investigate the role of axons in the maintenance or plasticity of glial and glycoconjugate rings associated with glomeruli by describing potential glial and ECM changes in the immature postnatal rat $\mathrm{OB}$ after unilaterally injecting a neurotoxin (zinc sulfate) into the olfactory epithelium and allowing for regeneration of olfactory axons to occur centrally. Our previous study (Gonzalez et al., 1993) suggests that the gross positioning of glomeruli is controlled by the overall positioning of TN/C-6S-PG; however, the present data suggest that formation of TN/C-6S-PG in the precise ring pattern is dependent upon the presence of olfactory axons.

\section{Materials and Methods}

Animals. Twenty postnatal day 5 (PD5) Sprague-Dawley rats (Zivic Miller) were ice anesthetized and $20 \mu \mathrm{l}$ of a neurotoxin ( $10 \%$ zinc sulfate in distilled water; Sigma Chemicals) was injected into the nasal cavity after making a small incision in the left nasal bone. A small piece of cotton was used to cover the incision and keep the solution in place. After 5,10 , or 20 d the rats were anesthetized by Metofane (2,2-dichloro1,1-difluoroethyl methyl ether) inhalation and killed by transcardiac perfusion using $4 \%$ paraformaldehyde in phosphate buffer. The tissue was postfixed overnight in the same solution, passed through a sucrose gradient $(10 \%, 20 \%$, and $30 \%)$ and cryostat sectioned. The olfactory epithelium of the right side was not disturbed and was used as the control. Immature postnatal rats were chosen, because at this stage glomeruli are well shaped and distinct, although immature. We believe that glial cells and axonal arbors might be most susceptible to experimental perturbations at this time.

Immunocytochemistry. Ten micrometer adjacent sections were reacted overnight with one of the following antibodies: olfactory marker protein (OMP) (courtesy of Dr. Frank Margolis, Roche Institute of 

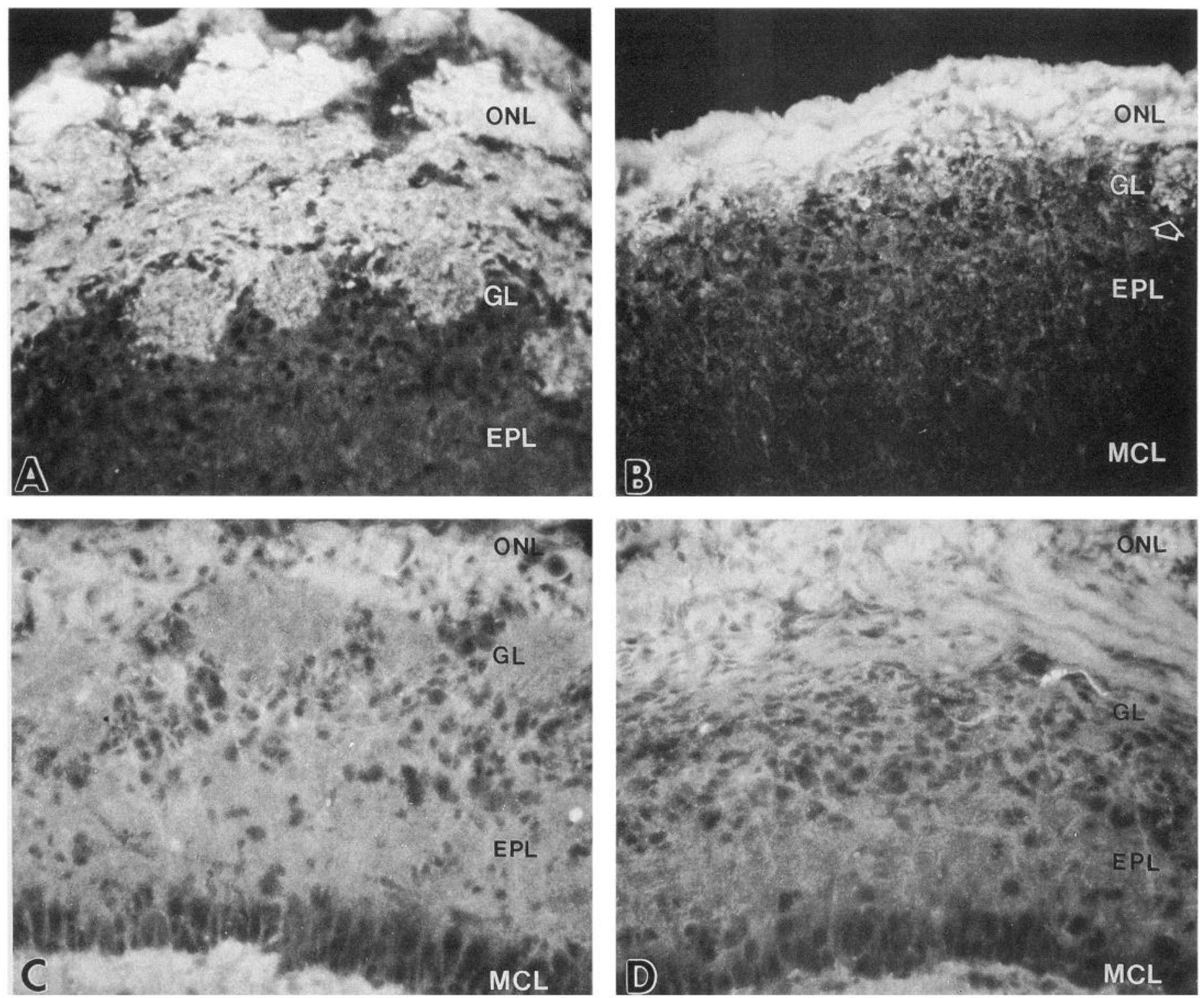

Figure 2. Pattern of glomeruli after $5 \mathrm{~d}$ of the neurotoxin injection in coronal sections of the OB. $A$, OMP-like immunoreactivity in the control side. Observe the characteristic glomeruli in the GL. B, OMP-like immunoreactivity in the experimental side shows a significant decrease in the number of glomeruli in this region, while OMP-positive axons are still present in the ONL. Note a remaining glomerulus (arrow). $C$, TUJ1 staining in the control side shows glomeruli in the GL. Observe that $\beta$-tubulin-like immunoreactivity is stronger in the ONL and below the MCL. $D$, TUJ1 staining in the experimental side shows no glomeruli in the GL, while $\beta$-tubulin-like immunoreactivity is still strong in the ONL. $O N L$, olfactory nerve layer; $G L$, glomerular layer; $E P L$, external plexiform layer; $M C L$, mitral cell layer. Magnification, $400 \times$.

Molecular Biology; diluted 1:200 in BSA/PBS), which reacts with olfactory axons; TUJ1 (courtesy of Dr. Anthony Frankfurter; diluted 1:3000 in dilution buffer), a monoclonal antibody that is specific for a neuronspecific type III $\beta$-tubulin isoform (Lee et al., 1990); CS-56 [Sigma Chemical Company; diluted 1:200 in 5\% NGS (normal goat serum)/ PBS], which is specific for the GAG portion of native chondroitin sulfate proteoglycan and binds to the 6-sulfated moiety; tenascin (TN), also known as cytotactin (courtesy of Dr. K. Crossin, Rockefeller University; diluted 1:300 in 5\% NGS/PBS); anti-glial fibrillary acidic protein (antiGFAP; Accurate Chemical; diluted 1:500 in dilution buffer).

After incubation with the primary antibody, the tissue was washed with the appropriate buffer a' ${ }^{\prime} d$ incubated with the specific biotinylated secondary antibody (1:200, $1 \mathrm{hr})$ : RAG IgG (Vector Labs) for OMP, GAM IgG (Chemicon International, Inc.) for TUJ1, GAM IgM (Chemicon International Inc.) for CS-56, and GAR IgG (Sigma Immuno Chemicals) for TN and GFAP. Following removal of the secondary antibody, the tissue was washed and incubated $30 \mathrm{~min}$ in strepavidin conjugated to Texas red (1:100; Amersham). The sections were rinsed and coverslipped in Citifluor (Citifluor Ltd.) and viewed on a Leitz Orthoplan 2 fluorescent microscope.

Glomeruli quantitation. In order to describe any changes in the number of glomeruli 5, 10, and $20 \mathrm{~d}$ after the zinc sulfate injection, control and experimental OMP-immunoreactive glomeruli at the rostral end of the bulb were counted over a distance of $750 \mu \mathrm{m}$ of coronal tissue sections. Five sections, $10 \mu \mathrm{m}$ each, were counted around their entire perimeter. Each section was separated from the next by about $150 \mu \mathrm{m}$. The average size of a glomerulus ranged from 50 to $100 \mu \mathrm{m}$; thus, the numbers counted represent different glomeruli and not the repeated counting of the same glomerulus in the different sections. OMP staining was chosen to identify the axonal aspect of the glomeruli. It describes clearly the shape of olfactory axon terminals that take the shape of glomeruli. We have focused our attention largely on the olfactory axons and associated astrocytes. It is important to stress, however, that other components of the glomeruli (like periglomerular cells and mitral cell 

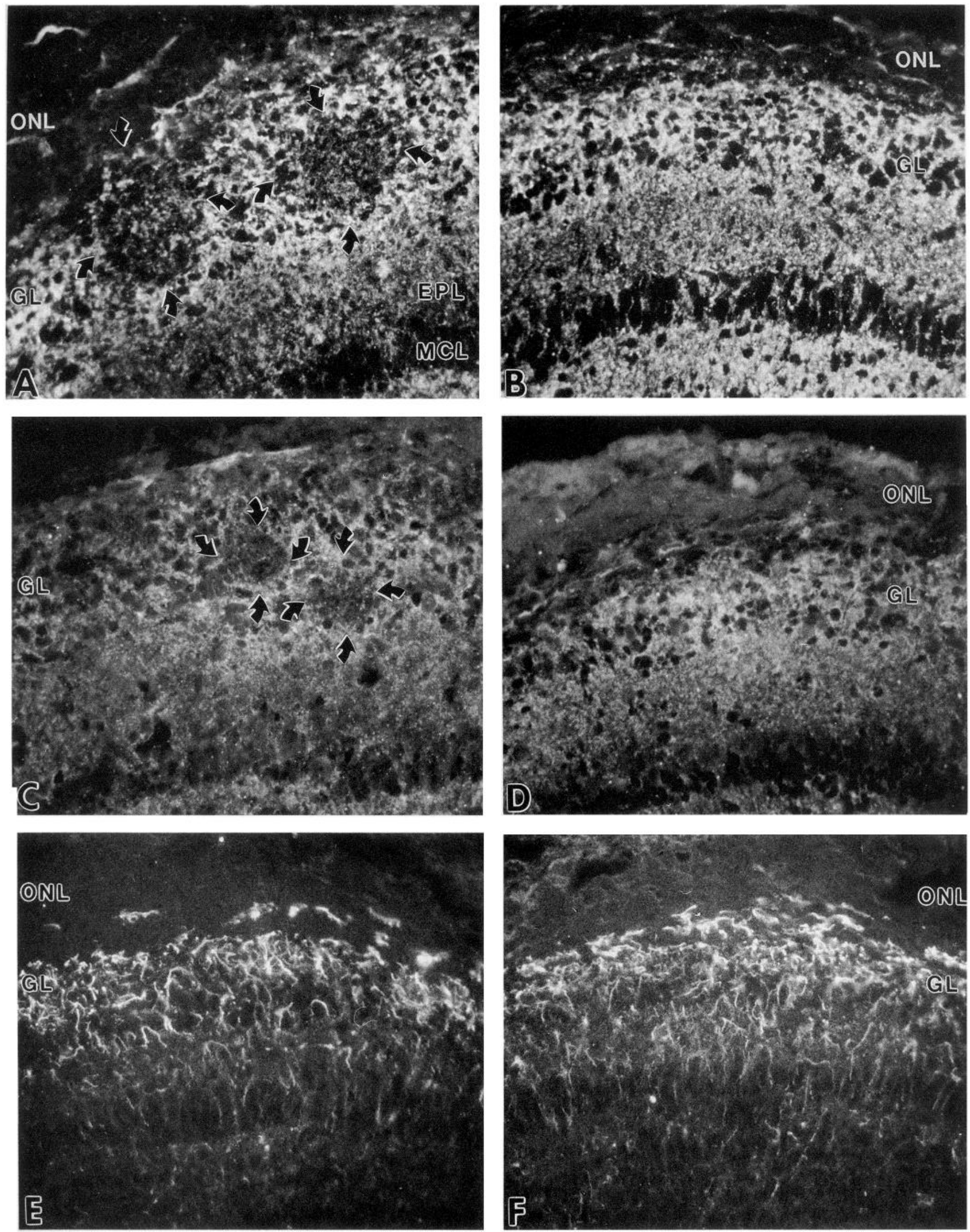

Figure 3. Glia and glycoconjugate matrix is shown in coronal sections of the $\mathrm{OB}, 5 \mathrm{~d}$ after the neurotoxin injection. $A$, CS-56 staining shows CSPG containing "rings" (arrows) around glomeruli in the GL of the control side. B, CS-56 staining in the experimental side shows no glomeruli in the GL and a similar pattern of holes, as seen with TUJ1. C, TN staining in the control side shows a few "rings" (arrows) in the GL. D, TN staining in the experimental side lacks glomeruli. $E$, GFAP staining in the control side shows the pattern of astrocytes in the OB. Note that GFAP-like immunoreactivity is stronger in the GL. $F$, GFAP staining in the experimental side shows a similar pattern of astrocytes as in the control (E). $O N L$, olfactory nerve layer; $G L$, glomerular layer; $E P L$, external plexiform layer; $M C L$, mitral cell layer. Magnification, $400 \times$. 
dendrites) may also be affected by deafferentation. For this reason, Nissl staining was done.

Nissl staining. Adjacent coronal sections of the $\mathrm{OB}$ were stained with cresyl violet ( $0.4 \mathrm{gm}$ in $100 \mathrm{ml}$ of distilled water; Aldrich) for $5 \mathrm{~min}$. Sections were then rinsed in $50 \%, 70 \%, 80 \%, 90 \%$, and $100 \%$ ethyl alcohol, 5 min each. Afterward, the sections were dipped briefly in xylene and mounted in Permount.

\section{Results}

Five or ten days after zinc sulfate injection

The neurotoxin injection did not kill all olfactory neurons or their axons. The overall result was a $71.7 \%$ (after $5 \mathrm{~d}$ ) or $82.3 \%$ (after $10 \mathrm{~d}$ ) decrease in the number of glomeruli in the injected side (left) as compared to the control side (right). These results are summarized in Figure 1.

Olfactory marker protein (OMP) antibodies were used in this study to describe the pattern of olfactory axons in the olfactory bulb (OB), while TUJ1 antibodies were used to describe the overall pattern of axons in the same tissue. The normal pattern of glomeruli in the $\mathrm{OB}$ is shown with OMP-like immunoreactivity in the control side (Fig. $2 A$ ). Five days after zinc sulfate injection into the left olfactory epithelium, there was a $71.7 \%$ decrease in the number of glomeruli in the glomerular layer (GL) of the OB (Figs. 1, 2B). The overall normal pattern of axons in the $O B$, including olfactory and mitral cell axons, is shown with $\beta$-tubulin immunoreactivity (TUJ1) (Fig. 2C). TUJ1 was used mainly to eliminate the possibility that the decrease in the number of glomeruli was due to downregulation of OMP staining rather than axon elimination. Indeed, $\beta$ - tubulin immunoreactivity in neurotoxin-lesioned animals also showed no glomerular pattern in the GL, suggesting that the decrease in number of glomeruli in the injected side (Fig. 2D) occurred because of a loss of olfactory axons that normally bundle. Some surviving olfactory axons not in a glomerular configuration persisted in the glomerular region.

Chondroitin-6-sulfate-containing proteoglycan (C-6S-PG) and tenascin (TN) were found associated with glial fibrillary acidic protein (GFAP)-positive astrocytes in the developing OB (Gonzalez et al., 1993). The normal pattern of C-6S-PG and TN in the shape of rings is shown in the control OB (Fig. $3 A, C$, respectively) at PD10. Five days after the neurotoxin injection on PD5 in the left olfactory epithelium, the ring pattern was disturbed (Fig. 3B,D). Noteworthy was the fact that the GL on the experimental side (Fig. $3 B, D$ ) was considerably narrower than the control (Fig. $3 A, C$ ). However, GFAP staining was similar in both cases (Fig. $3 E, F$ ). It is not clear why shrinkage of the GL occurred, but it seems to be a reasonable consequence of the decrease in the number of olfactory axons. We observed that the TN/C-6S-PG glomeruli rings were only present around the remaining small number of well-shaped glomeruli in the $O B$ (observed by double labeling with OMP and TN and CS-56 antibodies, respectively; data not shown). Elsewhere, the expression of TN/C-6S-PG was more homogeneous and disorganized in the GL (Fig. 3B,D). Importantly, the expression of GFAP did not change significantly in the experimental side (Fig. $3 F$ ) as compared to the control side (Fig. $3 E$ ).

Ten days after the neurotoxin injection in the left olfactory nasal epithelium, the decrease in the number of glomeruli was $82.3 \%$ (Fig. 1) in the corresponding OB. A similarly disrupted pattern of glomeruli and matrix rings was also found in the GL (Fig. 4). Not all olfactory axons were killed by the neurotoxin injection, but, rather, the number that were killed was sufficient enough to affect axon glomerular organization. In addition, the pattern of cells that normally surround the axonal glomeruli was also disturbed (see Fig. $7 A, B$ ).

\section{Twenty days after zinc sulfate injection}

At this stage, many olfactory axons had recovered from the lesion and reorganization of their axons and/or regeneration from the nasal epithelium was evident as new glomeruli appeared in the GL. Figure 1 summarizes these results. The $29 \%$ decrease in the number of glomeruli is much less than that observed after $5 \mathrm{~d}(71.7 \%)$ or $10 \mathrm{~d}(82.3 \%)$ after the injection. Thus, glomeruli reformed between 10 and $20 \mathrm{~d}$ postlesion.

Using OMP antibodies, a high number of glomeruli were found in both control (Fig. $5 A$ ) and $20 \mathrm{~d}$ experimental (Fig. 5B) OBs. Normal, well-shaped glomeruli were present in the experimental $\mathrm{OB}$ (Fig. $5 B$ ). New glomeruli were also evident with TUJ1 antibodies (Fig. 5D). As glomeruli reappeared, TN/C-6S$P G$ immunoreactivity was reexpressed in rings around the new glomeruli (Fig. 6A-D). Again, at this later stage, the expression of GFAP was similar in both control (Fig. $6 E$ ) and experimental (Fig. $6 F$ ) sides. Note that at this stage there is a higher density of GFAP-positive astrocytes inside rather than around the glomeruli. We also observed that in the GL the ring-like periglomerular cell pattern that had become disturbed at 5 and $10 \mathrm{~d}$ after the neurotoxin injection was now restored around each glomerulus (Fig. 7C,D).

\section{Discussion}

We have used a variety of immunohistochemical markers to study glial and ECM changes in the olfactory bulb (OB), after the administration of a neurotoxin (zinc sulfate) in the olfactory epithelium. Our study suggests that an interaction between regenerating olfactory axons and cells that have associated glycoconjugate matrix, is necessary in order to control the formation of TN/CS-PG in the precise ring pattern around individual glomeruli. Although we are not certain that this particular bulb ECM is produced by glia, it is clearly associated with them. Evidence confirming TN/C-6S-PG ECM production by glia comes from in vitro studies (Goodman et al., 1993; Canning et al., 1994) and in situ hybridization studies (Laywell et al., 1992), where it was shown that OB and cerebellar astrocytes do make these ECM components. Although it is possible that there is a contribution from neurons, as shown by in situ hybridization studies (Margolis and Margolis, 1993), we did not see any staining in neuronal cell bodies. Our results also suggest that the change in patterning of matrix in the vicinity of the glomeruli border and core is not simply dependent on the physical rearrangement of glia, but rather on the physical presence of olfactory axons.

It is important to stress that glia in the GL (Bailey and Shipley, 1993), as well as matrix layering in the early bulb (Gonzalez et al., 1993), are organized. Bailey and Shipley (1993) have shown that very early on, glial cells in the presumptive GL form into a "tuft," which corresponds to the region where axons coalesce to form the glomerulus. They suggested that a subpopulation of glia that are axon growth permissive could help direct glomeruli formation by forming a prepatterned template or by responding quickly to a signal from the axons. We have shown that after killing olfactory neurons and lesioning olfactory axons, which are the main effects of the neurotoxin injection, both axonal glomeruli and glycoconjugate "rings" disappeared in the GL. However, the astrocyte processes themselves, albeit GFAP positive, maintained their "normal" patterned distribution. This 

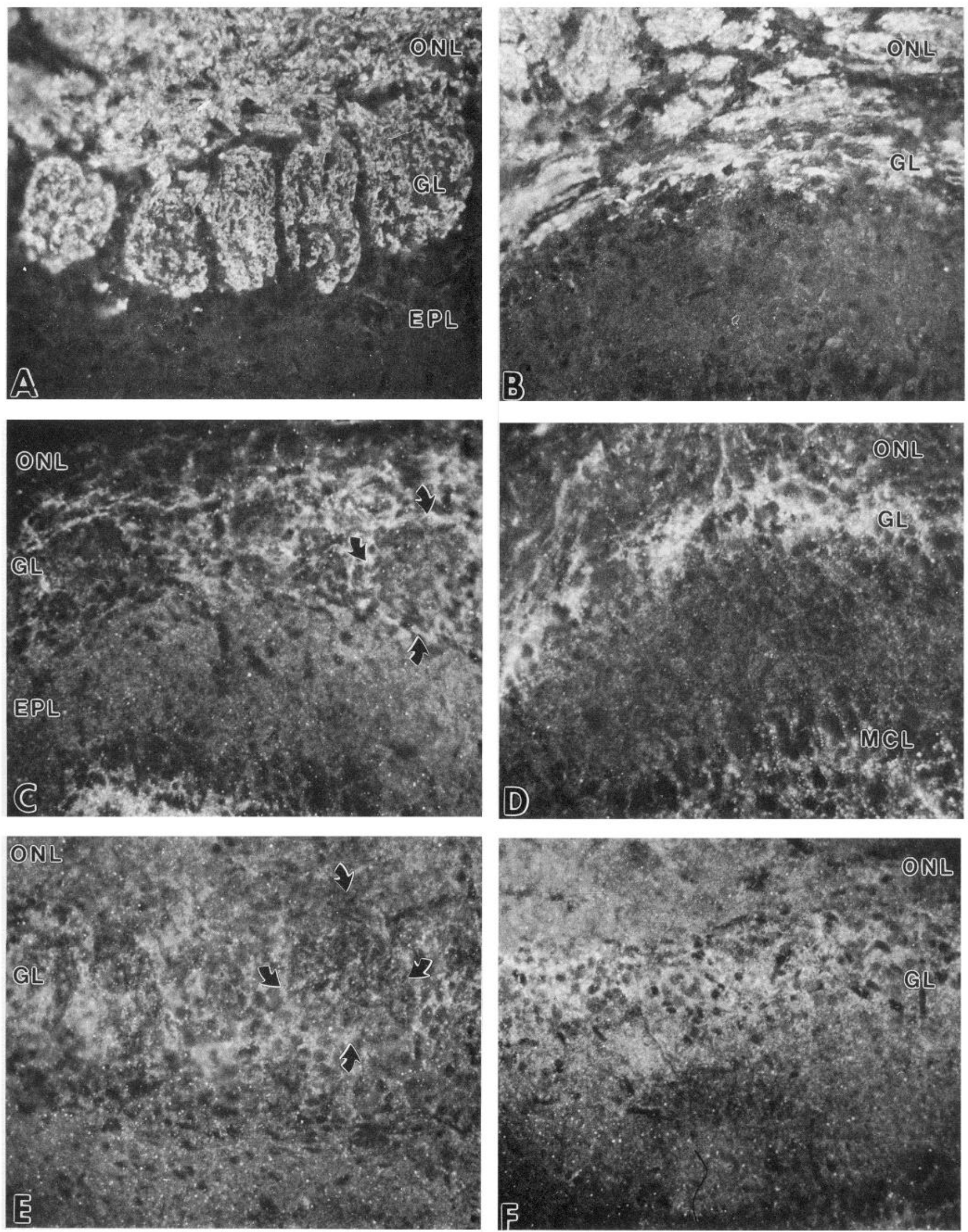

Figure 4. Olfactory axons and ECM molecules in coronal sections of the OB, $10 \mathrm{~d}$ after neurotoxin injection. A, OMP-like immunoreactivity in the control side. $B$, OMP-like immunoreactivity in the experimental side shows staining in the ONL and GL. $C$, CS-56 staining in the control side shows a few CS-PG containing "rings" (arrows show one ring) in the GL. D, CS-56 staining in the experimental side shows a uniform pattern lacking glomeruli in the GL. $E$, TN staining in the control side shows a few TN-like immunoreactive "rings" (arrows show one ring) in the GL. $F$, TN staining in the experimental side lack "rings" in the GL. $O N L$, olfactory nerve layer; $G L$, glomerular layer; $E P L$, external plexiform layer; $M C L$, mitral cell layer. Magnification, $400 \times$. 

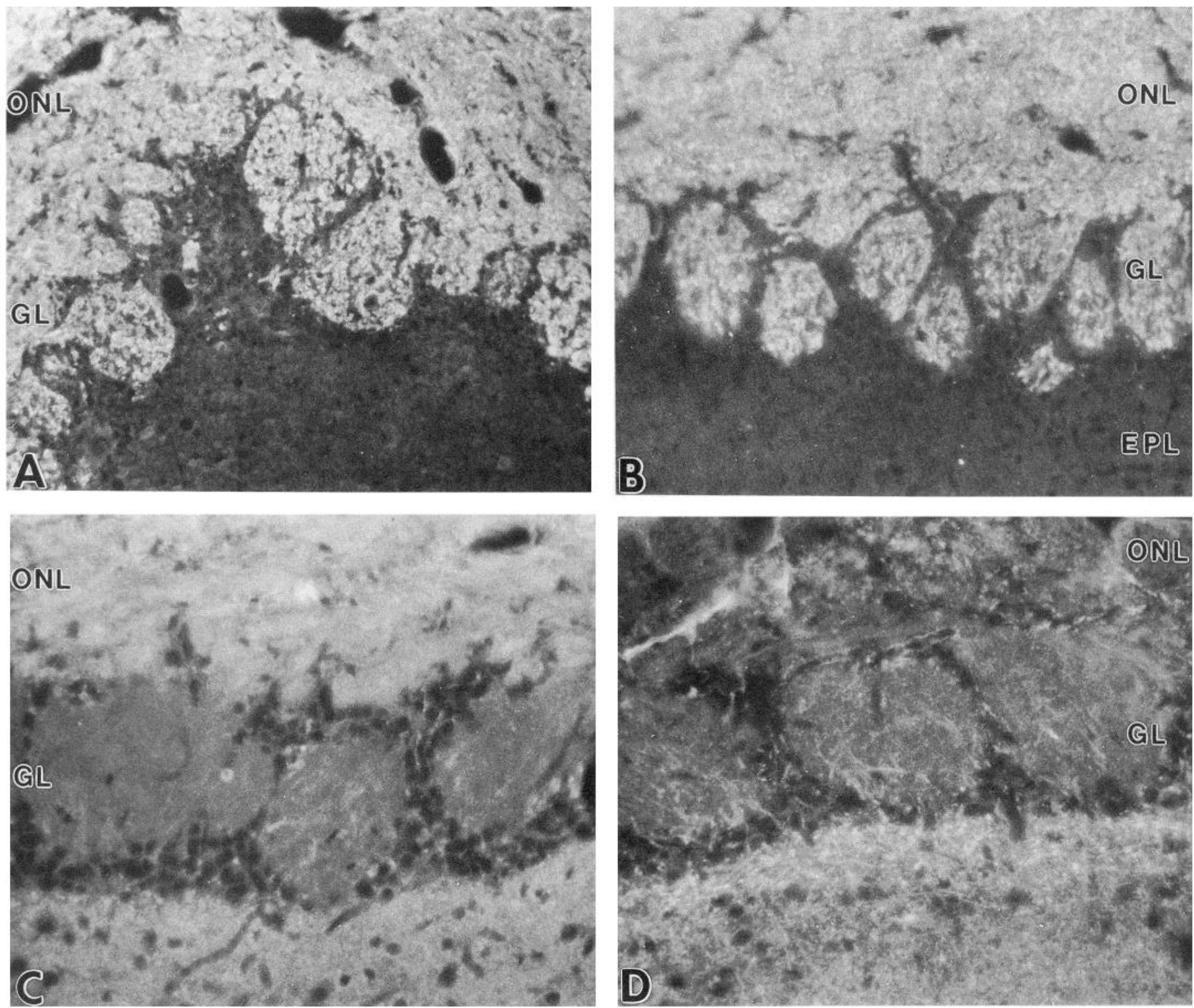

Figure 5. Labeling of olfactory axons with OMP and of $\beta$-tubulin-containing axons with TUJ1 in coronal sections of the OB, $20 \mathrm{~d}$ after neurotoxin injection. $A$, OMP-like immunoreactivity in the control side. $B$, OMP-like immunoreactivity in the experimental side shows new glomeruli in the GL. $C$, TUJ1 staining in the control side. $D$, TUJ1 staining in the experimental side confirms the finding of new glomeruli in $(B)$. $O N L$, olfactory nerve layer; $G L$, glomerular layer; $E P L$, external plexiform layer; $M C L$, mitral cell layer. Magnification: $A$ and $B, 250 \times ; C$ and $D, 400 \times$.

may mean that astrocytes "sense" alterations in the damaged olfactory axons, perhaps responding to activity changes (Zaremba et al., 1989), reactive microglial cells, or altered trophism, and as a result alter their glycoconjugate matrix pattern. The lack of astroglial hypertrophy was somewhat unexpected, since GFAP expression and astroglial size usually increase after a trauma or lesion. One explanation may be that since the experimental animals were immature, the gross astrocyte response was relatively diminished, an observation that has been made repeatedly in deafferented young animals (Carlstedt, 1987; Pindzola et al., 1993).

\section{Regeneration in the $O B$ and other systems}

It has been suggested that in the CNS, regenerative failure may be due to mechanical factors (Reier and Houle, 1988; Fawcett et al., 1989) or to macroglial-derived molecular inhibitors
(Schwab, 1990; Snow et al., 1990; McKeon et al., 1991; Petroski et al., 1991; Bovolenta et al., 1993; Fok-Seang et al., 1993; Geisert and Bidanset, 1993; Pindzola et al., 1993) much like those present in the bulb during normal development (Gonzalez et al., 1993). Unlike other primary sensory axons innervating the CNS, the olfactory axons are unique in that they can be replaced centrally following an injury. Previous studies have described the ability of new olfactory neurons to replace degenerating olfactory axons in the CNS after sectioning the nerve (Monti-Graziadei and Graziadei, 1979; Graziadei and MontiGraziadei, 1980; Monti-Graziadei et al., 1980; Doucette et al., 1983), partially removing the OB (Monti-Graziadei and Graziadei, 1992), or completely removing the OB (Graziadei et al., 1978). This regenerative ability may be reinforced by the ensheathing cells (Barnett et al., 1993), Schwann-like cells that wrap olfactory axons and are present in the ONL and GL of 

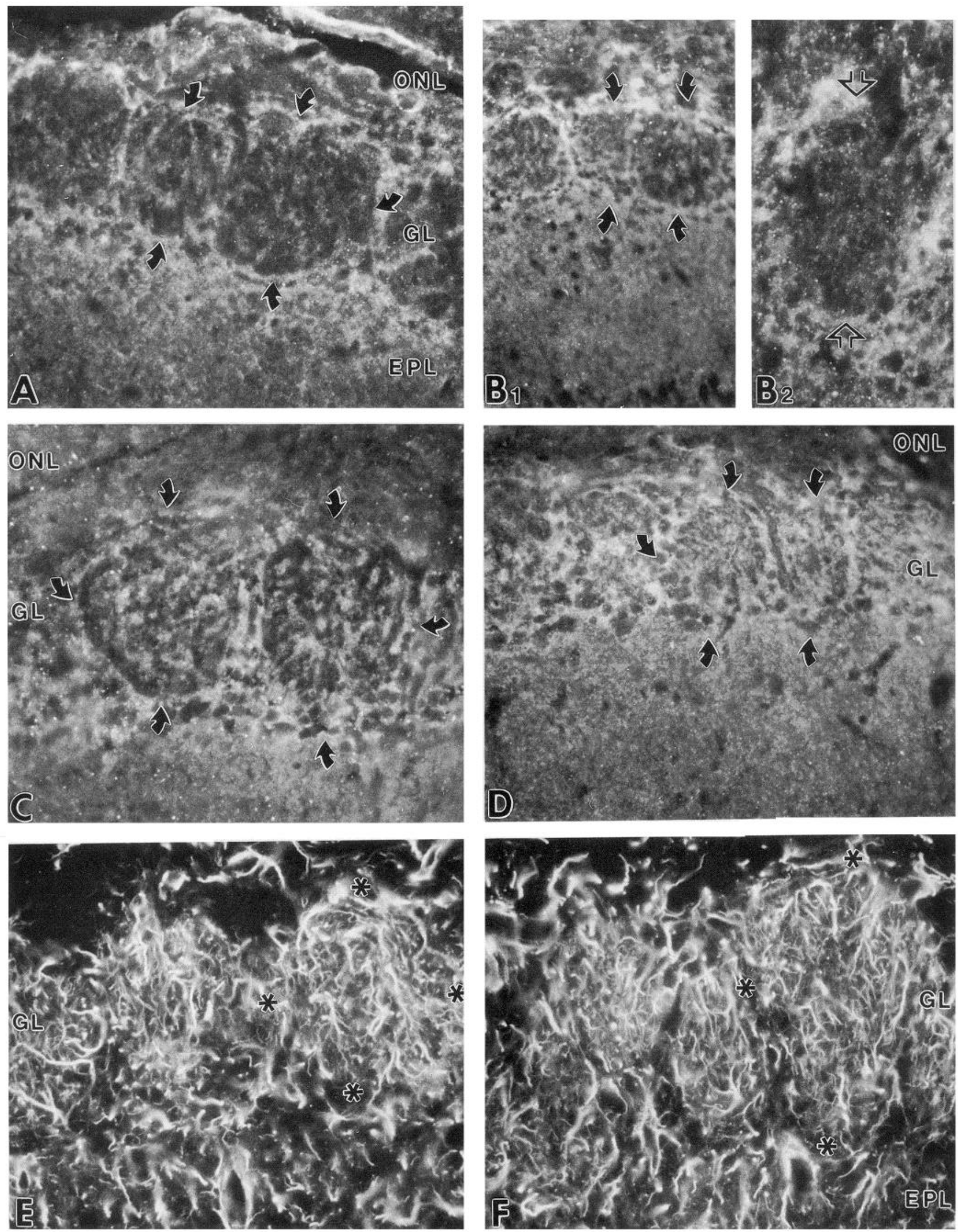

Figure 6. Glia and ECM in coronal sections of the OB, after $20 \mathrm{~d}$ of neurotoxin injection. A, CS-56 staining in the control side (arrows show two rings). $B_{l}$, CS-56 staining in the experimental side shows the reappearance of CS-PG containing "rings" (arrows). $B_{2}$, A glycoconjugate "ring" (arrows) in higher magnification. $C$, TN staining in the control side (arrows show two rings). $D$, TN staining in the experimental side shows rings 

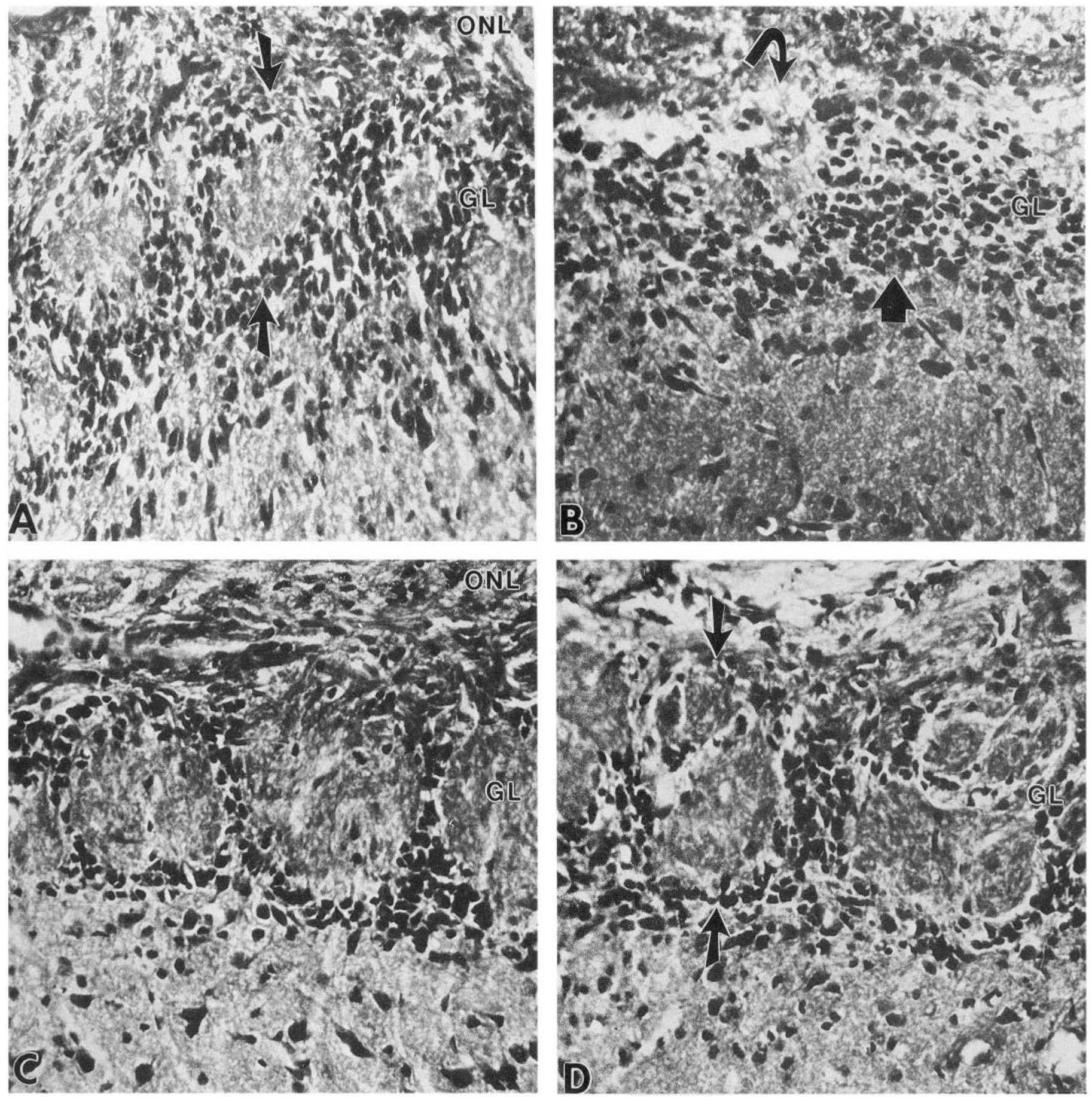

Figure 7. Nissl staining of adjacent sections of $\mathrm{OB} 10$ and $20 \mathrm{~d}$ after the neurotoxin injection. $A$, Control section after $10 \mathrm{~d}$ shows glomeruli in the GL surrounded by many periglomerular cells (arrows). B, Experimental section after $10 \mathrm{~d}$ shows a region in the GL with many randomly organized periglomerular cells (arrow) and a remnant glomerulus (curved arrow). Observe that in this region the pattern of periglomerular cells is disturbed and that they do not form glomerular "ring" as normally occurs. $C$, Control section after $20 \mathrm{~d}$ shows the normal pattern of glomeruli in GL. $D$, Experimental section after $20 \mathrm{~d}$ shows a similar pattern of glomeruli and periglomerular cells (arrows) in the GL. ONL, olfactory nerve layer; $G L$, glomerular layer. Magnification, $400 \times$.

(arrows). Compare the expression of C-6S-PG and TN, in the shape of rings, in control and experimental OB. E, GFAP staining in the control side shows astrocytes from the center of the OB to peripheral layers. $F$, GFAP staining in the experimental side shows a similar pattern as in the control $(E)$. Asterisks demark one glomerulus encapsulated and infiltrated with GFAP-positive astrocytes in $E$ and $F$. $O N L$, olfactory nerve layer; $G L$, glomerular layer; $E P L$, external plexiform layer; $M C L$, mitral cell layer. Magnification: $A, D, E$, and $F, 400 \times ; B_{l}, 250 \times ; B_{2}$ and $C, 500 \times$. 
the OB. Perhaps, the growth-promoting cell adhesion and trophic molecules produced by these cells following injury (Raisman, 1985; Doucette, 1990; Goodman et al., 1993), and the intimate relationship between these cells and the olfactory axons along the entire pathway from the mucosa to the center of the glomerular ring, may support regeneration of olfactory axons. Another factor leading to regeneration may be the ability of certain subpopulations of the bulb astroglia to respond in a growth-promoting manner upon arrival of the peripheral axons.

What is the underlying cellular mechanism by which the geometry of ECM expression changes in the GL after neurotoxin treatment? There are several possible explanations. First, there could be physical rearrangement of processes, or whole cells, that are secreting these ECMs. Although we did not see any obvious movements of GFAP-immunoreactive cells, immunolabeling of static sections with GFAP antibodies is not sufficient to eliminate this possibility. In fact, Nissl staining did reveal a change in the pattern of periglomerular cells. Second, there could be heterogeneous populations of astrocytes in the bulb, one type in the core and another in the surround of the glomerulus, that respond differently to the presence of axons. Indeed, Bailey and Shipley (1992) and Goodman et al. (1993) have shown that the bulb is composed of heterogeneous populations of glia, and that these various populations can make differential amounts of axon growth inhibitors such as CS-PG and TN (Gonzale 2 et al., 1993; Goodman et al., 1993). It is possible that astroglia with axon growth-promoting properties when in association with certain axons, are those that infiltrate glomeruli cores while nonpermissive, relatively nonmalleable astroglia encapsulate them. As developing or regenerating olfactory axons approach the GL, the core population of glial cells might rearrange their matrix pattern to permit the regenerating axons to grow into the GL, but the outer population in the ring blocks growth from going further. Downregulation of axon growth-inhibiting glycoconjugate matrix may be one of several important keys to regeneration in the OB (as well as normal glomerular development), making this region at the edge of the adult CNS unlike others (e.g., DREZ of spinal cord), where reactive astroglial inhibitory matrices persist and may block centrally regenerating sensory axons indefinitively (Pindzola et al., 1993). If we can uncover the mechanisms that underlie plasticity of ECM patterning in the bulb, then we may begin to understand how to reduce inhibitory matrices in other regions of the CNS, where regeneration fails.

\section{References}

Allison AC (1951) Olfactory discrimination. Ann Psychol 50:107113.

Bailey MS, Shipley MT (1992) Astrocyte subtypes in the rat olfactory bulb: morphological heterogeneity and differential laminar distribution. J Comp Neurol 328:501-526.

Bailey MS, Shipley MT (1993) Glia in the rat olfactory bulb: cell type heterogeneity in roles in development. $\mathrm{PhD}$ thesis, University of Cincinnati.

Barnett SC, Hutchins AM, Noble M (1993) Purification of olfactory nerve ensheathing cells from the olfactory bulb. Exp Biol 155:337350 .

Bovolenta P, Wandosell F, Nieto-Sampedro M (1993) Characterization of a neurite outgrowth inhibitor expressed after CNS injury. Eur J Neurosci 5:454-465.

Brittis PA, Canning DR, Silver J (1992) Chondroitin sulfate as a regulator of neuronal patterning in the retina. Science 255:733-736.

Canning DR, McKeon RJ, DeWitt DA, Perry G, Wujek JR, Freder- ickson RCA, Silver J (1993) $\beta$-Amyloid of Alzeheimer's disease induces reactive gliosis that inhibits axonal outgrowth. Exp Neurol 124:289-298.

Carlstedt T, Dalsgaar CJ, Molander C (1987) Regrowth of lesioned dorsal fibers into the spinal cord of neonatal rats. Neurosci Lett 74: 14-18.

Cole GJ, McCabe CF (1991) Identification of a developmentally regulated keratan sulfate proteoglycan that inhibits cell adhesion and neurite outgrowth. Neuron 7:1007-1018.

Cooper NGF, Steindler DA (1986a) Lectins demarcate the barrel subfield in the somatosensory cortex of the early postnatal mouse. J Comp Neurol 249:157-169.

Cooper NGF, Steindler DA (1986b) Monoclonal antibody to glial fibrillary acidic protein reveals a parcellation of individual barrels in the early postnatal mouse somatosensory cortex. Brain Res 380:341348.

Crossin KL, Hoffman S, Tan SS, Edelman GM (1989) Cytotactin and its proteoglycan ligand mark structural and functional boundaries in somatosensory cortex of the early postnatal mouse. Dev Biol 136: 381-392.

Doucette R (1990) Glial influences on axonal growth in the primary olfactory system. Glia 3:433-449.

Doucette JR, Kiernan JA, Flumerfelt BA (1983) The re-innervation of olfactory glomeruli following transection of primary olfactory axons in the central or peripheral nervous system. J Anat 137:1-19.

Erzurumlu RS, Jhavcri S (1992) Emcrgence of conncctivity in the embryonic rat parietal cortex. Cereb Cortex 2:336-352.

Ethell DW (1993) Neurite inhibiting factors from the developing and mature spinal cord. PhD thesis, The University of British Columbia.

Faissner A, Kruse J (1990) J1/tenascin is a repulsive substrate for central nervous system neurons. Neuron 5:627-637.

Fawcett JW, Housden E, Smith-Thomas L, Meyer RL (1989) The growth of axons in three-dimensional astrocyte cultures. Dev Biol 135:449-458.

Fok-Seang J, Rogers JH, Johnson RR, Keynes RJ, Fawcett JW (1993) Characterization of axon-growth permissive and inhibitory astrocyte cell lines. Soc Neurosci Abstr 19:1738.

Gascuel J, Mason C (1991) Developmental study of afferented and deafferented bee antennal lobes. J Neurobiol 22:795-810.

Geisert EE Jr, Bidanset DJ (1993) A central nervous system keratan sulfate proteoglycan: localization to boundaries in the neonatal rat brain. Dev Brain Res 75:163-173.

Goldberger ME (1974) Recovery of movement after CNS lesions in monkeys. In: Recovery of function after neural lesions (Stein D, ed). New York: Academic.

Goldberger ME, Murray M (1974) Restitution of function and collateral sprouting in cat spinal cord: the deafferented animal. J Comp Neurol 158:37-54.

Golgi C (1875) Sulla fina sruttura dei bulbi olfactorii. Riv Sper Freniat Med Leg Alien Ment 1:405-425.

Gonzalez MdeL, Silver J (1992) Role of astroglial extracellular matrix in the formation of rat olfactory bulb glomeruli. Soc Neurosci Abstr 18:620.

Gonzalez MdeL, Malemud CJ, Silver J (1993) Role of astroglial extracellular matrix in the formation of rat olfactory bulb glomeruli. Exp Neurol 123:91-105.

Goodman MN, Silver J, Jacobberger JW (1993) Establishment of rat olfactory bulb glial cell lines and comparison of their influences upon neurite outgrowth by retinal ganglion cell neurons. Brain Res 619: 199-213.

Graziadei PPC, Monti-Graziadei GA (1980) Neurogenesis and neuron regeneration in the olfactory system of mammals. III. Deafferentation and reinnervation of the olfactory bulb following section of the fila olfactoria in rat. $\mathrm{J}$ Neurocytol 9:145-162.

Graziadei PP, Levine RR, Graziadei GA (1978) Regeneration of olfactory axons and synapse formation in the forebrain after bulbectomy in neonatal mice. Proc Natl Acad Sci USA 75:5230-5234.

Grumet M, Flaccus A, Margolis RU (1993) Functional characterization of chondroitin sulfate proteoglycans of brain: interactions with neurons and neural cell adhesion molecules. J Cell Biol 120:815-824.

Hoffman S, Crossin KL, Edelman GM (1988) Molecular forms, binding functions, and developmental expression patterns of cytotactin and cytotactin-binding proteoglycan. An interactive pair of extracellular matrix molecules. J Cell Biol 106:519-532.

Kalb RG, Hockfield S (1990a) Large diameter primary afferent input 
is required for expression of the Cat-301 proteoglycan on the surface of motor neurons. Neuroscience 34:391-401.

Kalb RG, Hockfield S (1990b) Induction of a neuronal proteoglycan by the NMDA receptor in the developing spinal cord. Science 250 : 294-296.

Kliot M, Smith GM, Siegal JD, Silver J (1990) Astrocyte-polymer implants promote regeneration of dorsal root fibers into the adult mammalian spinal cord. Exp Neurol 109:57-69.

Laywell ED, Dorries U, Bartsch U, Faissner A, Schachner M, Steindler D (1992) Enhanced expression of the developmentally regulated extracellular matrix molecule tenascin following adult brain injury. Proc Natl Acad Sci USA 89:2634-2638.

Lee MK, Tuttle JB, Rebhun LI, Cleveland DW, Frankfurter A (1990) The expression and posttranslational modification of a neuron-specific beta-tubulin isotype during chick embryogenesis. Cell Motil Cytoskel 17:118-132.

Lochter A, Vaughan L, Kaplony A, Prochiantz A, Schachner M (1991) $\mathrm{J} 1 /$ tenascin in substrate-bound and soluble form displays contrary effects on neuritic outgrowth. J Cell Biol 113:1159-1171.

Margolis RK, Margolis RU (1993) Nervous tissue proteoglycans. Experientia 49:429-446.

McKeon RJ, Schreiber RC, Rudge JS, Silver J (1991) Reduction of neurite outgrowth in a model of glial scarring following CNS injury is correlated with the expression of inhibitory molecules on reactive astrocytes. J Neurosci 11:3398-3411.

Monti-Graziadei GA, Graziadei PPC (1979) Studies on neuronal plasticity and regeneration in the olfactory system: morphologic and functional characteristic of the olfactory sensory neuron. Neural Growth Differ 373-396.

Monti-Graziadei GA, Graziadei PPC (1992) Sensory reinnervation after partial removal of the olfactory bulb. J Comp Neurol 316:3244.

Monti-Graziadei GA, Karlan MS, Bernstein JJ, Graziadei PPC (1980) Reinnervation of the olfactory bulb after section of the olfactory nerve in monkey (Saimiri sciureus). Brain Res 189:343-354.

Oohira A, Matsui F, Katoh-Semba R (1991) Inhibitory effects of brain chondroitin sulfate proteoglycans on neurite outgrowth from PC12D cells. J Neurosci 11:822-827.

Oohira A, Matsui F, Watanable E, Kushima Y, Maeda N (1994) Developmentally regulated expression of a brain specific species of chondroitin sulfate proteoglycan, neurocan, identified with a monoclonal antibody $1 G 2$ in the rat cerebrum. Neuroscience, in press.

Perez RG, Halfter W (1993) Tenascin in the developing chick visual system: distribution and potential role as a modulator of retinal axon growth. Dev Biol 156:278-292.

Petroski RE, Grierson JP, Choi-Kwon S, Geller HM (1991) Basic fibroblast growth factor regulates the ability of astrocytes to support hypothalamic neuronal survival in vitro. Dev Biol 147:1-13.

Pindzola RR, Doller C, Silver J (1993) Putative inhibitory extracellular matrix molecules at the dorsal root entry zone of the spinal cord during development and after root and sciatic nerve lesions. Dev Biol 156:34-48.

Kaisman G (1985) Specialized neuroglial arrangement may explain the capacity of vomeronasal axons to reinnervate central neurons. Neuroscience 14:237-254.
Reier PJ, Houle JD (1988) The glial scar: its bearing on axonal elongation and transplantation approaches to CNS repair. Adv Neurol 47:87-138.

Ramon y Cajal S (1911) Histologie du systeme nerveux de l'homme et des vertebres, Vol II. Paris: Maloine. Reprint. Madrid: Instituto Cajal, 1955.

Schlaggar BL, O'Leary DDM (1991) Potential of visual cortex to develop an array of functional units unique to somatosensory cortex. Science 252:1556-1557.

Schwab ME (1990) Myelin-associated inhibitors of neurite growth and regeneration in the CNS. Trends Neurosci 13:452-456.

Silver J, Edwards MA, Levitt P (1993) Immunocytochemical demonstration of early appearing astroglial structures that form boundaries and pathways along axon tracts in the fetal brain. J Comp Neurol 328:415-436.

Snow DM, Lemmon V, Carino DA, Caplan AI, Silver J (1990) Sulfated proteoglycans present in astroglial barriers during development in vivo inhibit neurite outgrowth in vitro. Exp Neurol 109:111-130.

Steindler DA, O'Brien TF, Cooper NGF (1988) Glycoconjugate boundaries during early postnatal development of the neostriatal mosaic. J Comp Neurol 267:357-369.

Steindler DA, Cooper NGF, Faissner A, Schachner M (1989) Boundaries defined by adhesion molecules during development of the cerebral cortex: the $\mathrm{J} 1 /$ tenascin glycoprotein in the mouse somatosensory cortical barrel field. Dev Biol 131:243-260.

Steindler DA, O'Brien TF, Laywell E, Harrington K, Faissner A, Schachner M (1990) Boundaries during normal and abnormal brain development: in vivo and in vitro studies of glia and glycoconjugates. Exp Neurol 109:35-56.

Taylor J, Pesheva P, Schachner M (1993) Influence of janusin and tenascin on growth cone behavior in vitro. J Neurosci Res 35:347362.

Tolbert LP, Oland L (1990) Glial cells form boundaries for developing insect olfactory glomeruli. Exp Neurol 109:19-28.

Valverde F (1965) Studies on the piriform lobe. Cambridge, MA: Harvard UP.

Valverde F, Santacana M, Heredia M (1992) Formation of an olfactory glomerulus: morphological aspects of development and organization. Neuroscience 49:255-275.

Valverde F, Santacana M, Heredia M (1992) Formation of an olfactory glomerulus: morphological aspects of development and organization. Neuroscience 49:255-275.

Van der Loos H, Woolsey TA (1973) Somatosensory cortex: structural alterations following early injury to sense organs. Science 179:395398.

Weller WL, Johnson JI (1975) Barrels in cerebral cortex altered by receptor disruption in newborn, but not in five-day-old mice (Cricetidae and Muridae). Brain Res 83:504-508.

Woolsey TA, Wann JR (1976) Areal changes in mouse cortical barrels following vibrissal damage at different postnatal ages. J Comp Neurol 170:53-66.

Zaremba S, Guimaraes A, Kalb RG, Hockfield S (1989) Characterization of an activity-dependent, neuronal surface proteoglycan identified with monoclonal antibody Cat-301. Neuron 2:1207-1219. 